\title{
Alignment of atmospheric mineral dust due to electric field
}

\author{
Z. Ulanowski ${ }^{1}$, J. Bailey ${ }^{2}$, P. W. Lucas ${ }^{1}$, J. H. Hough ${ }^{1}$, and E. Hirst ${ }^{1}$ \\ ${ }^{1}$ Science and Technology Research Institute, University of Hertfordshire, Hatfield AL10 9AB, UK \\ ${ }^{2}$ Australian Centre for Astrobiology, Macquarie University, Sydney NSW 2109, Australia
}

Received: 9 July 2007 - Published in Atmos. Chem. Phys. Discuss.: 10 September 2007

Revised: 26 November 2007 - Accepted: 27 November 2007 - Published: 19 December 2007

\begin{abstract}
Optical polarimetry observations on La Palma, Canary Islands, during a Saharan dust episode show dichroic extinction indicating the presence of vertically aligned particles in the atmosphere. Modelling of the extinction together with particle orientation indicates that the alignment could have been due to an electric field of the order of $2 \mathrm{kV} / \mathrm{m}$. Two alternative mechanisms for the origin of the field are examined: the effect of reduced atmospheric conductivity and charging of the dust layer, the latter effect being a more likely candidate. It is concluded that partial alignment may be a common feature of Saharan dust layers. The modelling indicates that the alignment can significantly alter dust optical depth. This "Venetian blind effect" may have decreased optical thickness in the vertical direction by as much as $10 \%$ for the case reported here. It is also possible that the alignment and the electric field modify dust transport.
\end{abstract}

\section{Introduction}

Mineral dust in the atmosphere exerts significant indirect influence on radiation by acting as a source of nuclei for cloud formation. It also modifies both the shortwave solar radiation transmitted through to the surface and the longwave infrared radiation emitted to space. As an absorber of longwave radiation, dust can cause local warming of the atmosphere and modify atmospheric dynamics. There is also growing evidence that Saharan dust outbreaks may be reducing Atlantic hurricane activity (Evan et al., 2006; Wu, 2007). Yet significant gaps in the understanding of its role exist, in terms of both global and regional influences on weather and climate (Andreae et al., 2005; Haywood et al., 2005; Myhre et al., 2003; Yu et al., 2006; Mishchenko et al., 2007). Consequently, much effort has been directed at the development

Correspondence to: Z. Ulanowski

(z.ulanowski@herts.ac.uk) of global-scale measurement of aerosol properties, including both satellite and ground-based instruments such as sun photometers and lidar (Yu et al., 2006; Dubovik et al., 2006, http://aeronet.gsfc.nasa.gov).

However, existing satellite instruments can not be able to resolve the non-uniqueness problem associated with passive aerosol retrievals (Chowdhary et al., 2001; Mishchenko et al., 2007). In this context, polarimetry has much to offer, because multispectral, multiangle polarization measurements can uniquely recover many relevant aerosol parameters (Chowdhary et al., 2002; Boesche et al., 2006; Li et al., 2007). Similar considerations have recently led to major investment in polarization-measuring instruments for the remote sensing of clouds and aerosols: POLDER 1 and 2, PARASOL, the Research Scanning Polarimeter and the Aerosol Polarimetry Sensor (Mishchenko et al., 2007) .

It is also accepted that the nonsphericity of mineral dusts should be taken into account, particularly in remote sensing retrievals (Mishchenko et al., 2003; Volten et al., 2005; Dubovik et al., 2006; Kalashnikova and Sokolik, 2002; Kahnert et al., 2005). Polarimetry has a special role to play here because it is very sensitive to particle shape (Mishchenko et al., 2007; Dubovik et al., 2006; Mishchenko et al., 2002). However, polarimetry is also sensitive to particle orientation, a feature that has long been exploited in astronomy (Hough, 2007).

In this study, we report on high-sensitivity optical polarimetric observations which indicate the presence of vertically aligned particles in the atmosphere in the Canary Islands region, and show that the observations coincided with a Saharan dust episode. The presence of vertically aligned particles is unexpected, because aligned atmospheric particles, such as column or plate-shaped ice crystals, are typically oriented horizontally due to aerodynamic forces (Platt et al., 1978; Sassen and Benson, 2001). One exception concerns electrically active regions of storm clouds within which ice crystals are thought to align vertically (Vonnegut, 1965, Mendez,

Published by Copernicus Publications on behalf of the European Geosciences Union. 
1969; Hendry and McCormick, 1976; Krehbiel et al., 1996; Prigent et al., 2005, Weinheimer and Few, 1987). We therefore examine whether atmospheric electric fields not associated with storm clouds can produce vertical alignment of mineral dust aerosols, and if such alignment can account for the polarimetric observations. We also carry out a preliminary evaluation of the influence of the alignment on the interaction of shortwave radiation with a dust layer, and examine whether electric fields can influence gravitational settling of Saharan dust layers.

\section{Results}

\subsection{Polarimetry observations}

The observations were carried out from 27 April 2005 to 8 May 2005 with a new high-sensitivity astronomical polarimeter PlanetPol, which achieves fractional polarization sensitivities better than $10^{-6}$ with an absolute accuracy of about 1\% (Hough et al., 2006). The polarimeter was mounted on the William Herschel Telescope located on the island of La Palma at an altitude of $2340 \mathrm{~m}$. The measurements extended over a broad band of wavelengths from 590 to $1000 \mathrm{~nm}$ and were of polarized flux from four nearby stars which normally show little polarization. The angular aperture of the instrument was only 5", hence the measurement was that of extinction, and the error due to the inclusion of any scattering in the measured flux was likely to be negligible; furthermore, the polarized signal from background sky, measured directly in a second, identical channel, was insignificant. The observations were screened for the presence of clouds.

It was noted that observations on the nights from 3 to 7 May were characterized by increased linear dichroism, manifested by excess horizontal polarization component of transmitted light, which rose with the observation zenith angle. On 4 May the fractional polarization increased to a value of almost $5 \times 10^{-5}$ at the zenith angle of $56^{\circ}$. In contrast, observations before and after that period showed polarization near the detection level, typically $\approx 3 \times 10^{-6}$. The total flux was also reduced - see Sect. 2.2.2. Moreover, there was correlation between the magnitude of the observed polarization and the optical depth - for details see Bailey et al. (2007) ${ }^{1}$. We interpret the excess polarization as being due to an interaction of the starlight with nonspherical particles having their long axes preferentially oriented in the vertical direction, hence causing the vertical component of polarization to be scattered out of the observation path and/or absorbed more strongly for non-zero zenith angles of observation. The

\footnotetext{
${ }^{1}$ Bailey, J., Ulanowski, Z., Lucas, P. W., Hough, J. H., Hirst, E., and Tamura, M.: The effect of airborne dust on astronomical polarization measurements, Mon. Not. R. Astron. Soc., submitted, 2007.
}

correlation of the observed excess polarization with the optical thickness of the dust layer is expected because dichroic polarization is an extensive property, unlike the polarization of scattering which is an intensive one. Hence its strength increases with the amount of material present in the path.

\subsection{Dust properties}

\subsubsection{Meteorological conditions}

The William Herschel telescope is located at the Observatorio de Roque de Los Muchachos on La Palma in the Canary Islands, coordinates $28.76064^{\circ} \mathrm{N}, 17.88164^{\circ} \mathrm{W}$ (see e.g. Google Maps at http://maps.google.com/maps? $\mathrm{t}=\mathrm{k} \& 1 \mathrm{l}=28.76064,-17.88164$ or Google Earth software http://earth.google.com/ where the vertical terrain relief can also be examined). The telescope is at an altitude of $2340 \mathrm{~m}$ near the crest of a caldera, approximately $90 \mathrm{~m}$ below the highest point of the mountain, which forms the bulk of the island. The altitude of the observatory puts it above the marine mixing layer, so observations above convective clouds are possible.

Ten-day airmass back-trajectories were computed using the NOAA HYSPLIT model with FNL meteorological data (Draxler and Rolph, 2003). The trajectories indicate that the airmass during the La Palma dust episode originated in the arid western Sahel and Sahara, more specifically in Mali and Mauritania within the box $15^{\circ} \mathrm{N}-25^{\circ} \mathrm{N}, 15^{\circ} \mathrm{W}-5^{\circ} \mathrm{E}$. This region is a major source of atmospheric mineral dust (Goudie and Middleton 2001). For brevity, we will henceforth refer to the dust as Saharan dust (SD). According to the model, the dust plume reached La Palma via an indirect route over the Atlantic and was at least six days old - see Fig. 1. Typically, individual trajectories terminating in La Palma at altitudes between $2500 \mathrm{~m}$ and $5000 \mathrm{~m}$ originated near ground level in Africa. Trajectories terminating at or below $2000 \mathrm{~m}$ had maritime origin and/or did not contain ascending air masses. SD intrusions affecting mainly the free troposphere and not the marine mixing layer (extending typically up to about $1500 \mathrm{~m}$ ) are characteristic of spring and summer months at the Canary Islands (Varela et al., 2003). Transport patterns containing anticyclonic gyration over the east Atlantic, with an SD layer undercut by a trade wind inversion over the marine mixing layer, are likewise considered to be common for SD episodes (Karyampudi et al., 1999).

Aerosol Index data obtained from the Ozone Monitoring Instrument (OMI, http://aura.gsfc.nasa.gov/instruments/omi/ index.html) showed that the Canary Islands were on the periphery of the main bulk of the dust cloud, which was present to the south-west - Fig. 2. MODIS level 2 aerosol data (http://modis-atmos.gsfc.nasa.gov) showed similar patterns, furthermore characterized by high spatial non-uniformity of aerosol optical depth. MODIS level 2 cloud products showed the presence of some cloud cover during the observations, but the vast majority of it was below the altitude of the 


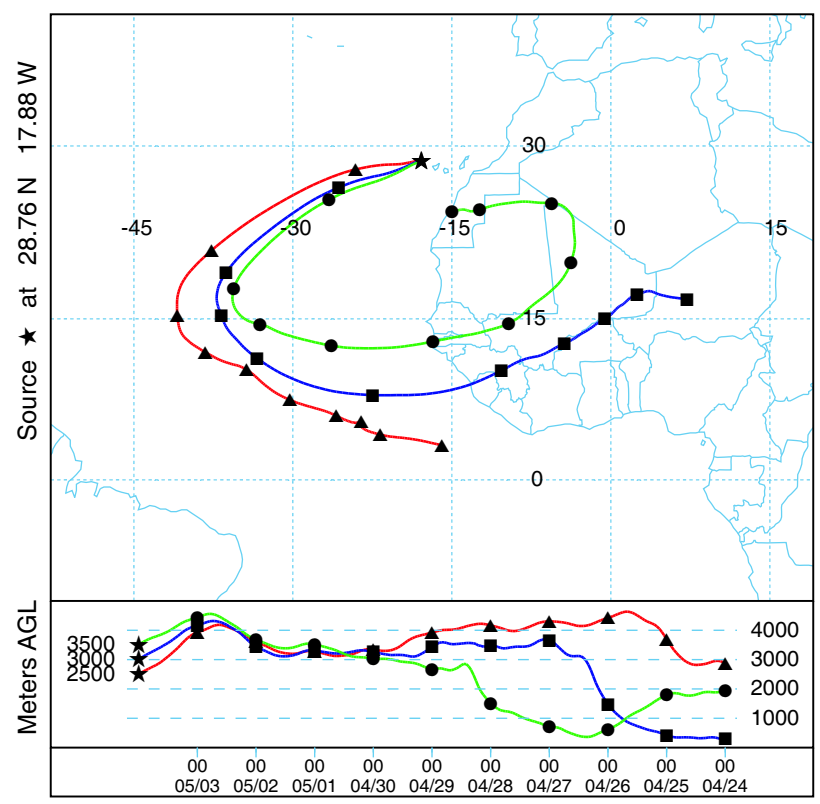

Fig. 1. 10-day backward airmass trajectories ending at 00:00 UTC on 4 May 2005, computed for final altitudes of 2500, 3000 and $3500 \mathrm{~m}$. The upper panel shows geographical location and the lower one the altitude above ground level in meters.

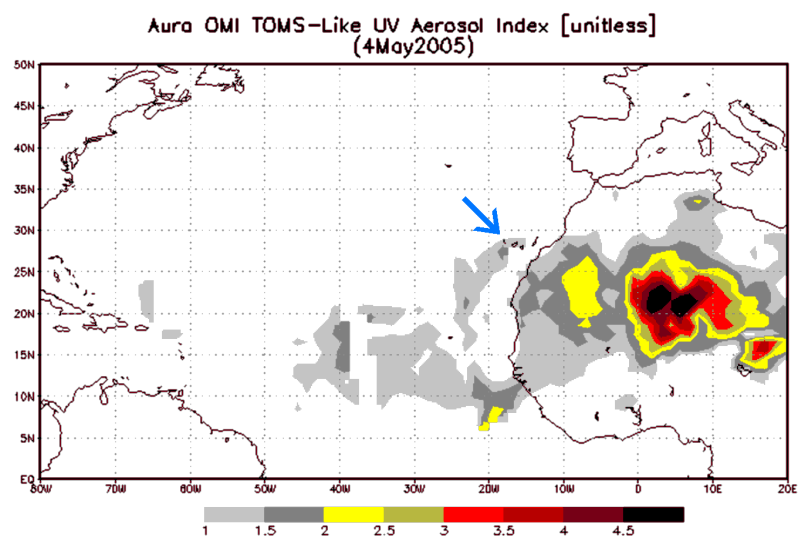

Fig. 2. OMI TOMS-like Aerosol Index for 4 May 2005. La Palma is arrowed.

observatory; some ice phase was indicated in the vicinity of the Canary Islands prior to but not during the dust episode. The low clouds are consistent with the presence of the trade wind inversion.

\subsubsection{Optical depth}

Optical properties of the SD layer over the Canary Islands were obtained from the AERosol RObotic NETwork (AERONET) Cimel sunphotometer in Santa Cruz on the nearby island of Tenerife (http://aeronet.gsfc.nasa.gov/). This site is at an altitude of $52 \mathrm{~m}$, about $180 \mathrm{~km}$ from La

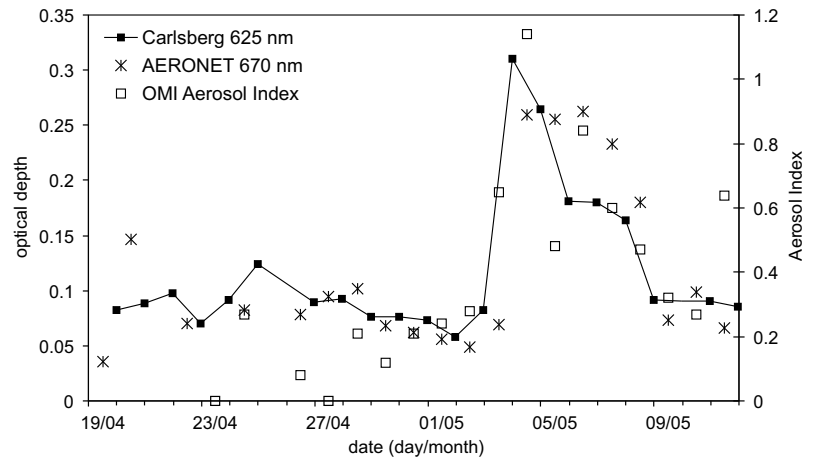

Fig. 3. Carslberg Meridian Telescope optical depth, AERONET (Santa Cruz) aerosol optical depth, and OMI Aerosol Index for a 5 by $5^{\circ}$ square centered on La Palma.

Palma. Particle size distributions, optical depth and effective radius were retrieved using the spheroidal particle method of Dubovik et al. (2006). Almucantar level 1.5 retrievals were cloud screened, and only sets for solar zenith angles above $20^{\circ}$, containing at least 21 measurement angles, and without anomalous distribution tails (almucantar retrieval type 0) were used for calculating daily averages. Additional optical depth data were obtained from the Carlsberg Meridian Telescope (http://www.ast.cam.ac.uk/ dwe/SRF/camc.html) co-located with the polarimeter. It showed that the zenith extinction at $625 \mathrm{~nm}$ increased from a typical value of 0.09 by between 0.08 and 0.22 . The optical depths derived from sun photometry and from the Carlsberg telescope were similar, indicating that the bulk of the dust cloud was present at a higher altitude. We note that while it is more common to observe reduced optical depth at the higher altitude corresponding to the William Herschel Telescope, comparable magnitudes at near sea level and mountaintop locations in the Canary Islands were documented in some cases (Smirnov et al., 1998). This pattern is consistent with the presence of the trade wind inversion. The two optical depth profiles are compared with the OMI Aerosol Index in Fig. 3.

\subsubsection{Size distributions}

The size distributions retrieved for the period of the dust episode showed elevated fine and coarse particle number concentrations in comparison with the periods both before and afterwards. The coarse mode was centered on $\approx 4 \mu \mathrm{m}$ size (expressed as diameter of equivalent volume sphere) see Fig. 4. The same distributions are plotted by particle surface area, i.e. $d A / d r$ to show the relative contributions to scattering and extinction from different sizes - see Fig. 5. On 4 May about $12 \%$ of particles by surface area were in the $4-$ $20 \mu \mathrm{m}$ size range in terms of the equivalent diameter. 


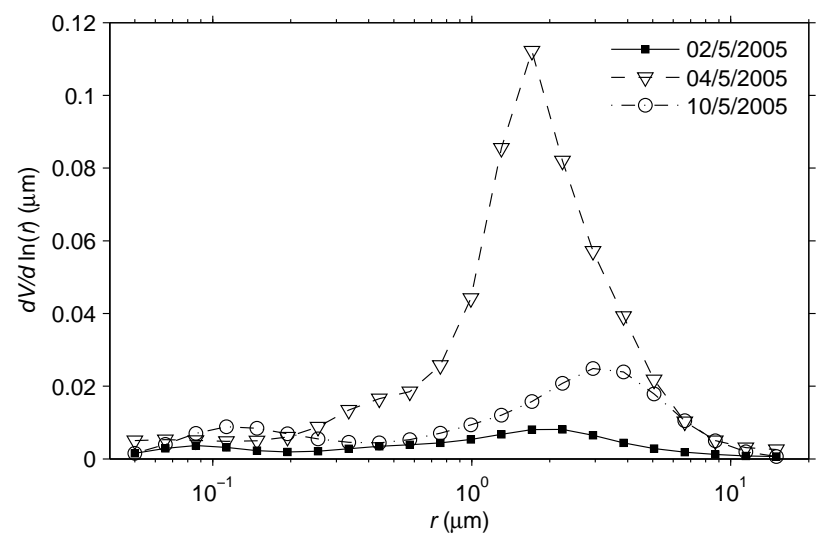

Fig. 4. Example columnar aerosol size distributions retrieved from the sun photometer at Santa Cruz, just before, during and just after the dust episode. The distributions are in terms of $V$, the total particle volume in the aerosol column over a unit ground surface area, on $\log$ scale, i.e. $d V / d \ln (r)$ (units $\mu \mathrm{m}$ ), where $r$ is the radius of the volume-equivalent sphere.

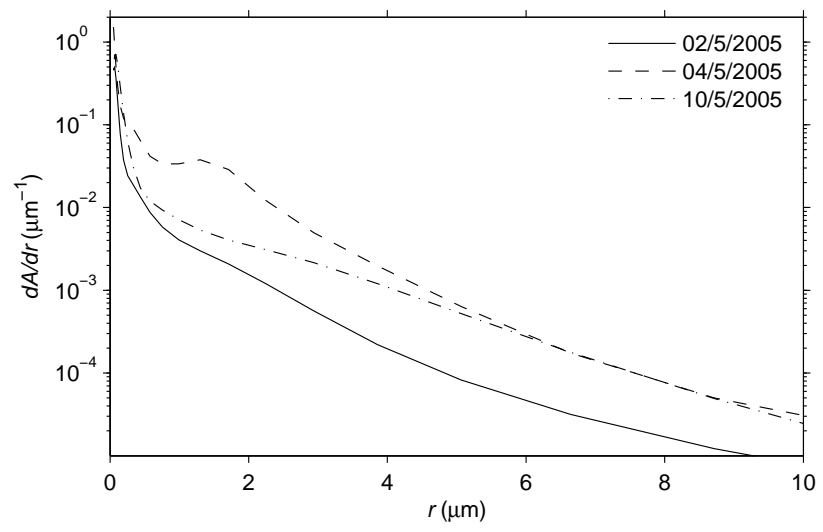

Fig. 5. As Fig. 4 but the columnar size distributions are in terms of $A$, the total projected area of the aerosol column over a unit ground surface area, for equal width size bins, i.e. $d A / d r$ (units $\mu \mathrm{m}^{-1}$ ).

\subsection{Atmospheric electric field}

In this section we examine two alternative mechanisms that can lead to the presence of a strong electric field within a dust layer. The fair weather electric field strength is on average about $120 \mathrm{~V} / \mathrm{m}$ in clear atmosphere near ground level and it decreases quickly with altitude (Roble and Tzur, 1986; Gringel et al., 1986). However, the presence of aerosols, fog or haze lowers atmospheric conductivity and strengthens the electric field locally (Cobb 1968, Gringel et al., 1986; Brazenor and Harrison, 2005). For example, monthly averages of fair-weather field near London exceeded $500 \mathrm{~V} / \mathrm{m}$ in the first half of 20th century when pollution levels were high (Scrase, 1934; Harrison and Aplin, 2002), and the field strength showed very strong negative correlation with con- ductivity (Harrison and Ingram 2005). Furthermore, these early observations revealed approximately linear relationship between air resistivity and the concentration of condensation nuclei (Wright, 1933; Scrase, 1935). Concerning Saharan dust, more than a two-fold reduction of atmospheric conductivity within SD layers was observed by Gringel and Mühleisen (1978). The electric field within an SD layer at a $3 \mathrm{~km}$ high Alpine peak exceeded fair weather value by a factor of about two, while the current density remained approximately constant (Reiter, 1992). The influence of neutral aerosols on the electric field is a consequence of small ion scavenging by the atmospheric particles (Fuchs, 1963; Hoppel and Frick, 1986; Brazenor and Harrison, 2005). This attachment process creates large ions at the expense of small ions. Large ions have lower electrical mobility and thus decrease the electrical conductivity of the atmosphere. Since the global ionospheric potential which drives the fair weather atmospheric current is relatively constant, with diurnal variation caused by changes in global thunderstorm activity (Mühleisen, 1971; Roble and Tzur, 1986), a decrease in conductivity within the aerosol layer results in increased potential difference across it in accordance with Ohm's law, and hence in increased field strength (Gringel et al., 1986).

Aerosols can also alter the atmospheric electric field directly if the aerosol is charged. Dust particles colliding between themselves and with the underlying surface become charged due to triboelectric effects (Kamra, 1972; Smirnov, 1999). This charge alone can produce a strong field within the dust cloud. It can be shown using Gauss's law that the field near the bottom of a thin, uniformly charged layer at low altitude will be approximately $E=\Delta z \rho_{c} / \varepsilon_{0}$, where $\Delta z$ is layer thickness, $\rho_{c}$ is spatial charge density and $\varepsilon_{0}$ permittivity of free space. Measurements of the spatial charge density within dust clouds vary widely in magnitude; taking two examples, $3 \times 10^{-10} \mathrm{C} / \mathrm{m}^{3}$ (Oluwafemi and Ette 1974) and $3 \times 10^{-8} \mathrm{C} / \mathrm{m}^{3}$ (Kamra 1972), we obtain field strength values of $3 \mathrm{kV} / \mathrm{m}$ and $300 \mathrm{kV} / \mathrm{m}$, respectively, for a hypothetical $100 \mathrm{~m}$ layer. Furthermore, the fields may be enhanced due to charge separation taking place as a result of size-dependent settling rates: it appears that larger dust particles tend to be charged positively, and since they settle out faster, a dipole can form. irrespectively of the mechanism, observations show that normal atmospheric electric fields can become substantially increased in magnitude and reversed, depending on the horizontal position with respect to the cloud (Frier, 1960; Ette, 1971). Field strengths as high as $-20 \mathrm{kV} / \mathrm{m}$ have been observed at ground level during dust storms, in some cases tens of km from the source (Kamra, 1972; Smirnov, 1999; Harris, 1967). Similar values have been reported below volcanic plumes, and fields within the plumes can sometimes be high enough to initiate lightning (see Mather and Harrison, 2006 for a review). Much of recent research has concentrated on the possibility that dust storms provide a source of electrical activity in the Martian atmosphere (Melnik and Parrot, 1998; Farrell et al., 2004), and the conclusions are similar to 
those obtained for terrestrial dust.

We will now proceed to elucidate the mechanism of electric field generation within an uncharged aerosol layer by establishing a numerical relationship between the optical properties of the layer and the electric field. The ionic conductivity can be described by the equation (Gringel et al., 1986)

$\sigma=e^{-} \mu_{ \pm} n_{ \pm}$

where $e^{-}$is the elementary charge, $\mu_{ \pm}$is the mean ion mobility and $n_{ \pm}$the total number concentration of positive and negative ions. Under high aerosol loading, when aerosol attachment dominates over direct ion recombination, the ion balance equation can be written as (Brazenor and Harrison, 2005; Harrison and Aplin, 2002)

$q=n_{ \pm} \beta N$

where $q$ is the total ion (positive and negative) production rate, $\beta$ is the ion-aerosol attachment coefficient and $N$ aerosol number concentration. In general, $\beta$ depends on aerosol particle size and for an aerosol with a size distribution $N(r)$ Eq. (2) should be written as

$q=n_{ \pm} \int_{0}^{\infty} \beta(r) N(r) d r=n_{ \pm} \beta_{\mathrm{eff}} N$

where $\beta_{\text {eff }}$ is the effective attachment coefficient (Hoppel and Frick 1986). By combining Eqs. (1) and (3) we obtain

$\sigma=\frac{e^{-} \mu_{ \pm} q}{\beta_{\mathrm{eff}} N}$

The optical depth $\tau$ can be expressed as $\tau=\Delta z k_{\text {ext }}$ where $\Delta z$ is the geometric thickness of the layer, $k_{\text {ext }}$ the extinction coefficient (Mishchenko et al., 2002)

$k_{\mathrm{ext}}=\int_{0}^{\infty} s_{\mathrm{ext}}(r) N(r) d r=\bar{s}_{\mathrm{ext}} N$

$s_{\text {ext }}(r)$ and $\bar{s}_{\text {ext }}$ are the size-dependent and effective the extinction cross-section, respectively. The optical depth can therefore be written as

$\tau=\Delta z \bar{s}_{\text {ext }} N$.

We can now eliminate $N$ by combining (4) and (6) to obtain an equation connecting the conductivity and optical depth of an aerosol layer

$\sigma=\frac{e^{-} \mu_{ \pm} q \bar{s}_{\mathrm{ext}} \Delta z}{\beta_{\mathrm{eff}} \tau}$.

The atmospheric current density is determined through Ohm's law by the magnitude of the ionospheric potential $U$ and the columnar resistance $R_{c}$ of the atmosphere (Gringel et al., 1986):

$J=U / R_{c}$
The columnar resistance can be separated into two terms containing its fair-weather value in the absence of aerosol $R_{c 0}$ and an excess resistance $\Delta R$ due to the aerosol layer

$R_{c}=R_{c 0}+\Delta R=R_{c 0}+\Delta z\left(1 / \sigma+1 / \sigma_{0}\right) \approx R_{c 0}+\Delta z / \sigma$

where $\sigma$ and $\sigma_{0}$ are mean conductivities at the altitude of the aerosol layer with and without the aerosol, respectively, and we have assumed that $\sigma<<\sigma_{0}$, as would be the case in the presence of a dense aerosol layer. Assuming that the aerosol layer has large horizontal extent, Eq. (8) can now be rewritten as

$J \approx \frac{U}{R_{\mathrm{c} 0}+\Delta z / \sigma}$.

The average electric field strength $E$ within the aerosol layer can now be calculated as

$E=J / \sigma=\frac{U}{R_{\mathrm{c} 0} \sigma+\Delta z}$.

It now remains to substitute Eqs. (7) into (11) to provide the expression we seek, directly connecting the electric field strength with the optical depth

$E=\frac{U}{\Delta z\left(1+\frac{R_{\mathrm{c} 0} e^{-} \mu_{ \pm} q \bar{s}_{\mathrm{ext}}}{\beta_{\mathrm{eff}} \tau}\right)}$.

We should also consider the influence of surface topography on the electric field. Enhancement of the fair weather electric field on mountaintops has previously been observed, with field strengths as high as $300 \mathrm{~V} / \mathrm{m}$ (Cobb et al., 1967; Kocijan, 1998). While extensive measurements over a mountain site in Hawaii showed field strengths typical of flat ground (Cobb, 1968), this could be the consequence of the position of the site nearly $800 \mathrm{~m}$ below the peak, where the enhancement can be cancelled out (Tzur et al., 1985), as well as low aerosol concentration. Numerical computations for a gently-sloping mountain with a 7:1 diameter to height ratio give a 1.6 enhancement factor for the electric field strength, but a comparison with the Mauna Loa observations by Cobb (1968) indicates that the factor may be underestimated (Tzur et al., 1985). Electrostatic theory provides three-fold field enhancement at the top of an idealized hemispherical mountain, if homogeneous air conductivity is assumed (Schottky, 1923; Le Ny, 1981; Kasemir, 1977). The enhancement factor can be written for this case as $1+2\left(z_{0} / z\right)^{3}$ where $z$ is the altitude above base level and $z_{0}$ mountain height (hemisphere radius). By integrating this expression along a line extending from the mountain top to a maximum altitude $z_{1}$ we obtain an average enhancement factor

$$
\frac{1}{z_{1}-z_{0}} \int_{z_{0}}^{z_{1}}\left(1+2\left(z_{0} / z\right)^{3}\right) d z=1+z_{0} / z_{1}+\left(z_{0} / z_{1}\right)^{2}
$$

The average enhancement factors calculated from this formula are about 2.5 and 2.2 for a $500 \mathrm{~m}$ and $1000 \mathrm{~m}$ column, 


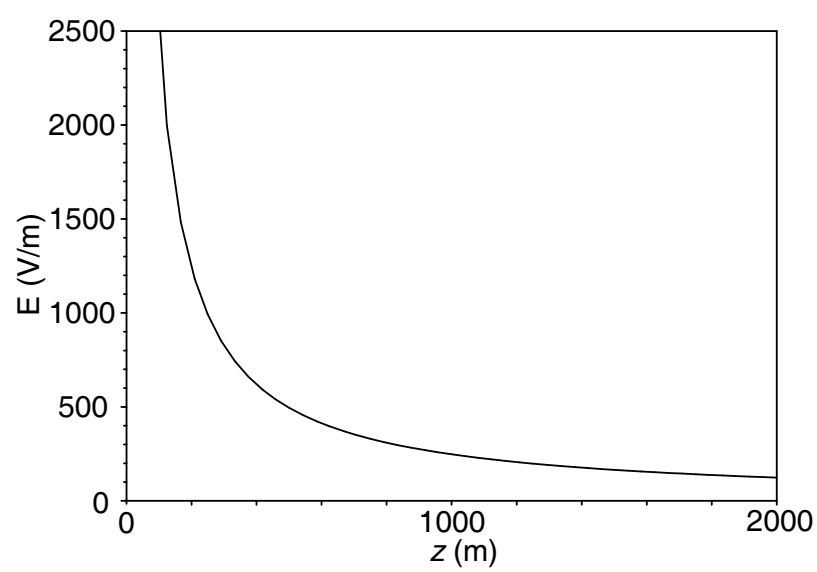

Fig. 6. Electric field strength as a function of aerosol layer thickness for optical depth of 0.31 , calculated from Eq. (12) with the topographic enhancement factor of two.

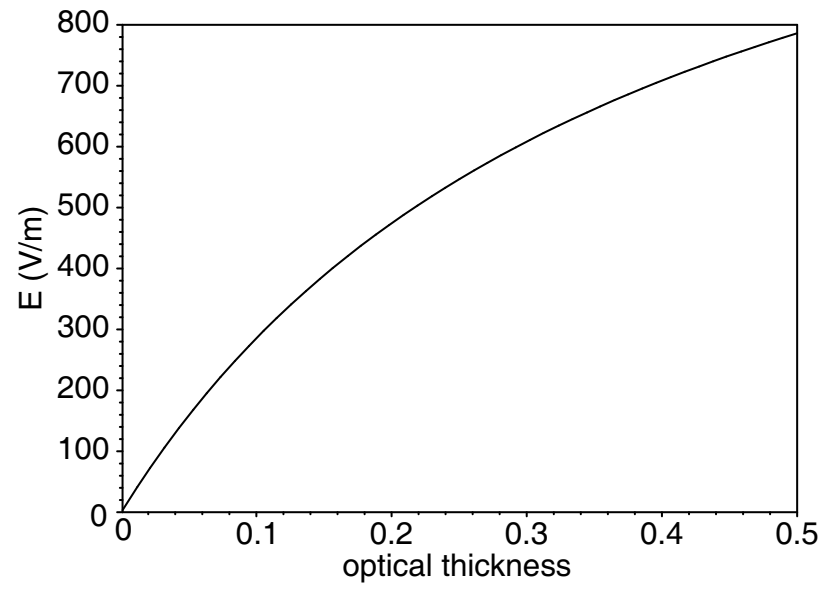

Fig. 7. Electric field strength as a function of aerosol optical depth calculated from Eq. (12) for an aerosol layer $400 \mathrm{~m}$ thick.

respectively, above a mountain of La Palma height $(2.3 \mathrm{~km})$. In the absence of data specific to the La Palma site we will henceforth apply a topographic enhancement factor of two to Eq. (12) etc.

Field strengths within an aerosol layer have been calculated from Eq. (12) as a function of the geometric thickness of the layer (Fig. 6) and optical thickness (Fig. 7). The mean ion mobility (Gringel et al., 1986) was corrected to the temperature $T$ and pressure $p$ at La Palma (285 K, 0.75 bar) using the Langevin rule $\mu_{ \pm}=\mu_{ \pm 0} T p_{0} / T_{0} p$ where the subscript 0 refers to standard conditions to give a value $\mu_{ \pm}=1.8 \times 10^{-4} \mathrm{~m}^{2} \mathrm{~V}^{-1} \mathrm{~s}^{-1}$. The total ion production rate was taken to be $q=9.8 \times 10^{6} \mathrm{~m}^{-3} \mathrm{~s}^{-1}$ and the columnar resistance of the atmosphere $R_{c 0}=5 \times 10^{16} \Omega \mathrm{m}^{2}$, a value characteristic of a mountain site (Cobb, 1968). While the attachment coefficient is proportional to size for larger par- ticles, this approximation breaks down below the radius of about $100 \mathrm{~nm}$ (Horrak et al., 1998). Therefore integration with size distributions according to Eq. (3) was used to estimate the effective value. For both the effective attachment and the effective extinction coefficients, trimodal lognormal distributions were fitted to the AERONET retrieved ones (so as to avoid abnormal fine mode), resulting in values of $\beta_{\text {eff }}=4.7 \times 10^{-11} \mathrm{~m}^{3} \mathrm{~s}^{-1}$ and $\bar{s}_{\text {ext }}=1.3 \times 10^{-12} \mathrm{~m}^{2}$ (corresponding to an effective radius of $0.46 \mu \mathrm{m}$ ), respectively.

\subsection{Particle alignment}

We consider a particle subjected to torques due to an electric field and fluid flow, both along the vertical direction, as well as to rotational Brownian motion. The probability density for the alignment angle under steady state conditions is given by Boltzmann's law (Fuchs 1964)

$P=\exp \left(-\frac{W_{E}+W_{H}}{k T}\right) \sin \theta$

where $W_{E}$ and $W_{H}$ are potential energy contributions due to the particle's orientation in the electric field and in the fluid flow, respectively, $k$ is the Boltzmann constant, $T$ temperature and $\theta$ particle orientation angle with respect to the vertical direction. The $\sin (\theta)$ factor originates from integration over the azimuth orientation angle. The electric field potential energy for a conducting prolate ellipsoid is (Fuchs, 1964; Lilienfeld, 1985)

$W_{E}=-2 \pi \varepsilon_{0} V E^{2}\left(\frac{\cos \theta^{2}}{X_{1}}+\frac{\sin \theta^{2}}{X_{2}}\right)$

where

$X_{1}=\left(\frac{a \ln (a+\sqrt{b})}{\sqrt{b}}-1\right) / b$

$X_{2}=a\left(a-\frac{\ln (a+\sqrt{b})}{\sqrt{b}}\right) / 2 b$

$b=a^{2}-1, a$ is the ratio of major to minor axis of the ellipsoid (aspect ratio), $\varepsilon_{0}$ the dielectric constant, $V$ the ellipsoid volume, $E$ the electric field strength and $\theta$ the angle between the major axis and the field direction (vertical). Conducting rather than dielectric particles are assumed because at low electric field frequencies aerosol particles can be considered to be conducting due to water adsorbed on their surface, even at low humidity (Fuchs, 1964; Lilienfeld, 1985).

The hydrodynamic alignment energy for an ellipsoid falling at low Reynolds number can be calculated as (Cox, 1965; Weinheimer and Few, 1987)

$W_{H}=29 \pi \rho v_{0}^{2} D^{3}|a-1|(a+2)^{2} \cos \theta^{2} / 2880$ 


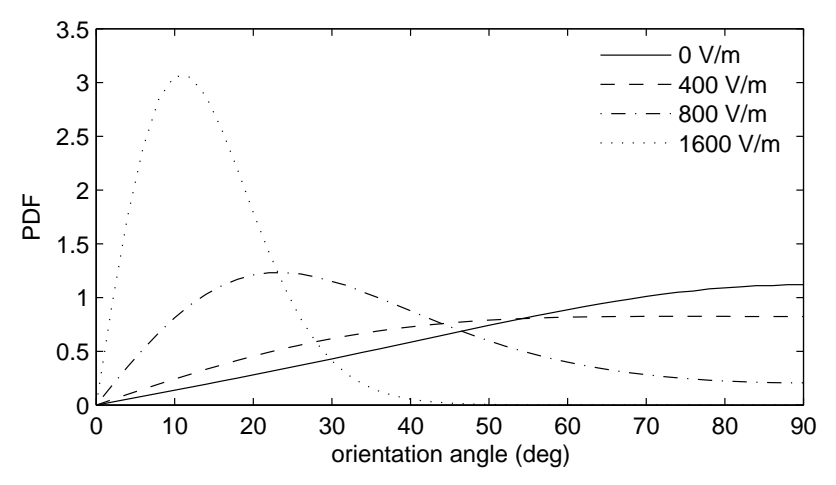

Fig. 8. Normalized probability distribution function of orientation angle of prolate ellipsoids with a long axis of $10 \mu \mathrm{m}$, aspect ratio of 1.5 and density is $2.6 \mathrm{~g} / \mathrm{cm}^{3}$, falling under gravity and subjected to a vertical electric field (strength shown in the legend).

where $\rho$ is the specific gravity of the medium (air) and $D$ the length of the minor axis (diameter) of the ellipsoid. The terminal velocity $v_{0}$ is calculated for simplicity for a prolate ellipsoid in random orientation (Clift et al.. 1978):

$v_{0}=\pi g \rho_{1} L^{3} / 6 \mu c a^{2}$

where $g$ is the gravitational acceleration, $\rho_{1}$ and $L$ particle density and the length of the major axis, respectively, $\mu$ the dynamic viscosity of the medium (air) and $c$ the flow resistance $c=3 \pi D \sqrt{b} / \ln (a+\sqrt{b})$.

Probability density distributions of the orientation zenith angle have been calculated from Eq. (14) for a range of field strengths and normalized to $1-$ see Fig. 8. Aspect ratio $a=1.5$ was assumed, which is typical of SD (Reid et al., 2003; Kalashnikova and Sokolik, 2002). In any case, the alignment was found not to be strongly dependent on the aspect ratio, especially for smaller grains, where alignment due to the electric-field dominates. Consequently, even moderately nonspherical particles can become aligned.

A better picture of particle alignment can be obtained by considering the influence of particle size. Figure 9 shows the mean orientation angle of ellipsoidal particles, computed for a range of field strengths, as a function of maximum particle dimension. The most interesting feature of the plot is the dominance of electric alignment over thermal fluctuations and aerodynamic alignment for a range of particle sizes, dependent on the field but centered on about $15 \mu \mathrm{m}$ maximum particle dimension. For the $1600 \mathrm{kV} / \mathrm{m}$ field strength particles above $\approx 5 \mu \mathrm{m}$ in maximum dimension ( $2 \mu \mathrm{m}$ equivalentvolume sphere radius) show significant alignment.

\subsection{Extinction modelling}

Calculations of polarized extinction were carried out for prolate spheroids of aspect ratio $a=3 / 2$ by computing the extinction matrix using the T-matrix method (Mishchenko

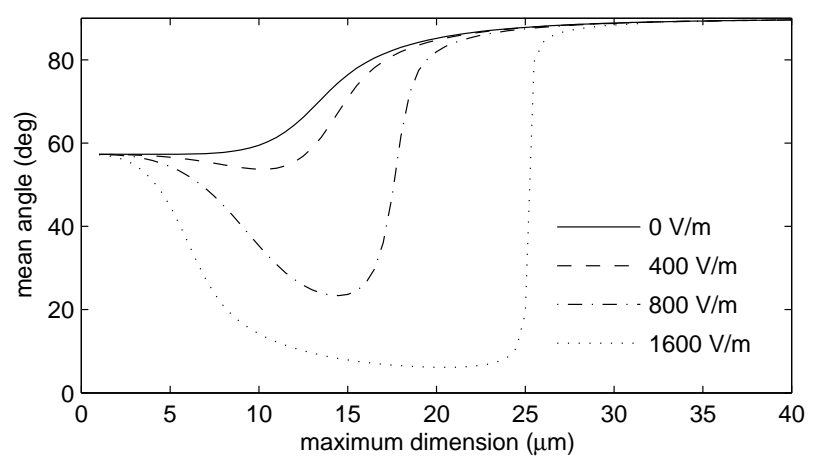

Fig. 9. Mean orientation angle of prolate ellipsoidal particles with aspect ratio $a=1.5$ and density is $2.6 \mathrm{~g} / \mathrm{cm}^{3}$, falling under gravity and subjected to a vertical electric field (strength shown in the legend).

2000). The calculation wavelength was $780 \mathrm{~nm}$ and the refractive index was taken to be 1.46-i0.006 - average value derived from sun photometer retrievals but also characteristic of silica-dominated mineral dust. Single scattering was assumed, i.e. the optical thickness was calculated as $\tau$ $\approx \sum K_{11}$, and the fractional polarization was calculated as the normalized second Stokes parameter $Q \approx-\sum K_{12}$ with respect to the vertical reference plane, where $\sum K_{i j}$ are elements of the extinction matrix summed over all particles in the (inclined) aerosol column - taking into account the airmass corresponding to the given zenith angle. To obtain this simplification advantage was taken of the fact that the light source was unpolarized, $\sum K_{12}<<1$, and the particles were axisymmetric (Mishchenko et al., 2002; Whitney and Wolff, 2002). The AERONET derived size distribution for 4 May 2005 (Figs. 4 and 5) was used for the summation, except that it was converted to number distribution and interpolated to give equivalent-volume radius bins with equal spacing of $0.1 \mu \mathrm{m}$. Fixed spheroid orientations were used in the computation, with size-dependent orientation angle distributions calculated from Eq. (14) for several field strengths.

A plot of the computed degree of horizontal polarization, defined as $-Q \approx \sum K_{12}$, is given in Fig. 10 as a function of the observation zenith angle, in comparison with the polarization excess observed on the nights of 3 and 4 May 2005 (for more details of the observations see Sect. 2.1). It should be pointed out that the rise of the polarization with zenith angle is due to both the vertical direction of preferential alignment (i.e. no transverse alignment is seen when the observation path becomes vertical) and airmass increase with zenith angle. A plot showing the fractional decrease in extinction due to particle alignment with respect to extinction due to non-aligned particles (in the absence of electric field), defined as $\sum K_{11}(0) / \sum K_{11}(E)-1$, is shown in Fig. 11 as a function of the field strength $E$ for several zenith observation angles. 


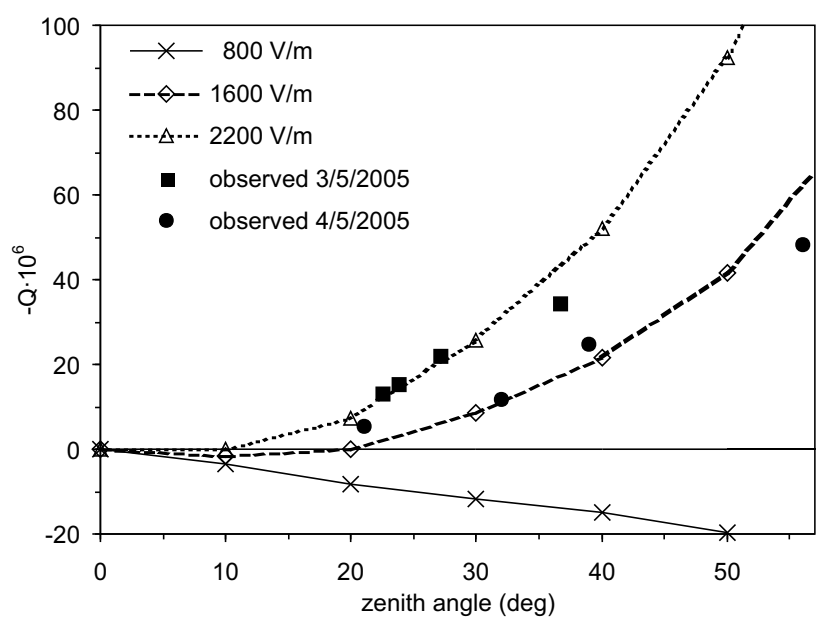

Fig. 10. Horizontal polarization excess of the transmitted flux, in parts per million. Open symbols and lines show computed polarization, plotted as a function of the observation zenith angle for several electric field strengths, as given in the legend. Closed symbols show observed polarization excess on the nights of 3 and 4 May 2005 the error bars on the observed values are typically $\pm 1.8 \mathrm{ppm}$.

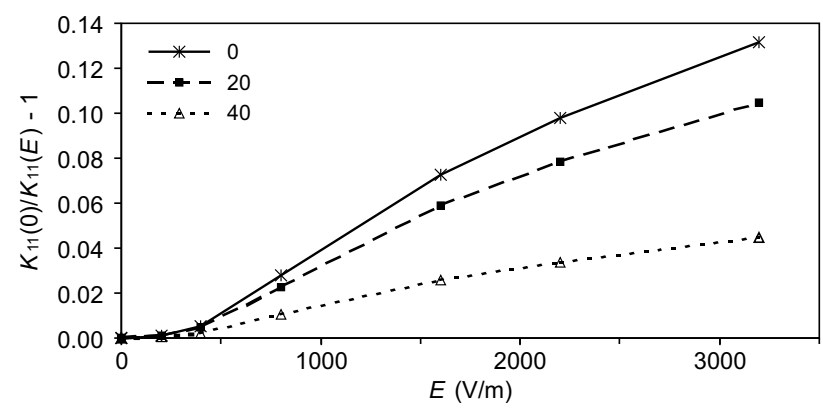

Fig. 11. Fractional decrease in extinction due to particle alignment as a function of the field strength, with respect to extinction for randomly oriented particles, for several zenith observation angles. The wavelength is $780 \mathrm{~nm}$.

\section{Discussion}

We have reported here high-sensitivity night-time polarimetric observations of an aerosol layer over the island of $\mathrm{La}$ Palma. The aerosol was likely to have originated in the western Sahel and Sahara and travelled along trajectories about six days in duration. The observations showed that transmitted starlight was polarized with small excess in the horizontal direction for non-zenith observation directions. Such polarization can be expected in the presence of dust grains aligned predominantly with their long axes vertical. Our modelling indicates that significant alignment is possible if atmospheric electric field with a vertical strength of the order of about $1 \mathrm{kV} / \mathrm{m}$ or more is present. We have also modelled dichroic polarization due to partially aligned dust using the T- matrix method. The results agree with the observed profiles of polarization as a function of zenith angle and indicate that during the observations in May 2005 the field strength was likely to have been about $2 \mathrm{kV} / \mathrm{m}$. It should be noted that the alignment effect is due to electric polarization of elongated grains, i.e. it does not depend on the grains themselves being charged per se. Furthermore, the results in Sects. 2.3 and 2.4 show that the presence of strong electric fields can be a consequence of the very existence of a dust layer, automatically fulfilling the condition for alignment provided that the optical depth is high enough and the layer is geometrically thin. Our estimates based on the observed optical depth and size distribution of the La Palma SD layer indicate that the required field strength could have been present provided that the SD layer was about $150 \mathrm{~m}$ thick, which is a possible but uncommon situation. However, alignment within a charged dust cloud would not be subject to the geometrically-thin layer constraint. Moreover, very large field strengths below dust clouds have been reported elsewhere, reaching tens of $\mathrm{kV} / \mathrm{m}$ (see Sect. 2.3). Therefore the presence of charged dust seems a more likely explanation for the observed alignment. Since field strength measurements in aged dust layers are not available, full evaluation of this hypothesis is not possible at present.

This appears to be the first observation of aligned atmospheric aerosol. We have not been able to find any accounts of vertical alignment of atmospheric particles apart from observations of ice crystals in clouds. Vonnegut (1965) provided an explanation for abrupt changes observed in the visual appearance of the tops of thunderstorm clouds by proposing that ice crystals were being aligned along the electric field. This supposition was confirmed mainly by polarized radar observations (Mendez, 1969; Hendry and McCormick, 1976; Krehbiel et al., 1996) and theoretical modelling (Weinheimer and Few, 1987). The occurrence of vertical alignment is well correlated with lightning activity (Prigent et al., 2005) - for a review see Caylor and Chandrasekar (1996). The process we are reporting is similar, except that it involves smaller particles and electric fields some two orders of magnitude weaker. It is also significant that dust particles are more long-lived than ice crystals, therefore more time is available for the field generation process, such as charge separation, and the alignment itself to occur. Lastly, due to the weaker fields, thermal and electric energies are comparable for smaller grains, which consequently align only weakly.

How widespread can be the occurrence of dust alignment in the atmosphere? While our evidence indicates that the influence of dust alignment on radiation can be strong, remote sensing (with the exception of the high-sensitivity dichroic extinction measurement) cannot be expected to provide unambiguous evidence of alignment because its effects are not uniquely different from those of particle size, shape and other factors. The only other evidence for the alignment that we have been able to locate comes, indirectly, from analysis of deposited dust, which indicates that particles with 
high aspect ratios are preferentially removed from dust transported over longer distances ( $\mathrm{Li}$ and Osada, 2007). In a companion article Li and Osada (2007a) explain the apparently increased settling rates of high aspect ratio particles by invoking vertical alignment, which would lead to reduced viscous drag. The authors then ascribe the alignment to flow shear. However, flow shear is not present during gravitational settling of dust, and aerodynamic forces lead to horizontal, not vertical orientation of atmospheric particles (Platt et al., 1978; Sassen and Benson, 2001; Weinheimer and Few, 1987), whereas the vertical alignment is consistent with the presence of electric fields as argued here.

We have shown that the effect is strongly size dependent: electric alignment will dominate over thermal fluctuations on the one hand, and aerodynamic alignment on the other hand, for a narrow range of particle sizes, a phenomenon found previously for ice crystals (Weinheimer and Few, 1987). The width of this size range increases with the electric field but the range is centered on the maximum dimension of the particle of about $15 \mu \mathrm{m}$ (12 $\mu \mathrm{m}$ equivalent diameter $)-$ Fig. 9 . Therefore, geographical and temporal extent of the alignment will depend on the presence of quite large particles. While gravitational settling is likely to remove larger particles over time (Maring et al., 2003), such particles are frequently present in mineral dusts plumes associated with SD storms (Goudie and Middleton, 2001; Middleton et al., 2001; Reid et al., 2003). For example, SD with the modal diameter of $9 \mu \mathrm{m}$ was observed over England, with particles between 10 and $20 \mu \mathrm{m}$ contributing more than $20 \%$ of the coarse mode by volume (Pitty, 1968), and the mean equivalent diameter of the coarse fraction of dust entering the ocean off the west coast of Africa peaked in May with a value of about $18 \mu \mathrm{m}$ (Ratmeyer, 1999).

Interestingly, it appears that some hitherto unknown atmospheric process counteracts gravitational settling of larger atmospheric dust particles (Maring et al., 2003), as models of long-range dust transport often underestimate the larger particle fraction (Colarco et al., 2003, Ginoux et al., 2001), and dust samples collected after fallout events show that large numbers of "giant" dust particles $(>62.5 \mu \mathrm{m})$ can be carried thousands of kilometers from their source (Middleton et al., 2001). In principle, aggregation of smaller particles might shift the size distribution towards larger sizes and in our context it may be relevant that aggregation of aerosol particles can be enhanced by charging under some circumstances (Clement et al., 1995). It is also possible that the settling is counteracted to some extent by the electric field itself, provided that gravitational separation of positively and negatively charged particles is taking place, leading to the emergence of a dipole. In effect, particles with opposite charges might then become coupled by attractive forces. Such coupling could effectively increase the projected area of larger aerosol particles, slowing down their settling. Examination of the size distribution in Fig. 5 shows that this "electrostatically-mediated aerodynamic breaking" could be quite significant due to the dominance of smaller particles in terms of projected area. Evaluation of this hypothesis is difficult at present, in the absence of in situ measurements of electrical properties, but a rough estimation can be attempted. To balance gravity a charge to mass ratio of $5 \times 10^{-3} \mathrm{C} / \mathrm{kg}$ is required in the postulated $2 \mathrm{kV} / \mathrm{m}$ field. The columnar mass of the La Palma aerosol can be estimated from the AERONET retrievals to have been about $2.6 \times 10^{-3} \mathrm{~kg} / \mathrm{m}^{2}$ on 4 May 2005 (most of which was within the coarse particle mode), implying a columnar charge of $\approx 10^{-5} \mathrm{C} / \mathrm{m}^{2}$. For a $1000 \mathrm{~m}$ thick layer this translates into a charge density of $10^{-8} \mathrm{C} / \mathrm{m}^{3}$. In comparison, charge densities higher than this value have been observed in dust clouds (Kamra, 1972), demonstrating that this hypothesis should be investigated further.

Our modelling indicates that neither the aerodynamic nor the electric alignment depends very strongly on the aspect ratio of the particle. Therefore even moderately nonspherical particles such as SD grains can become aligned. Moreover, the dust above La Palma may have been typical of Saharan dust episodes over a large geographical area, since the dust outbreak itself was unexceptional, as evidenced for example by the OMI aerosol index map for the 4 May (Fig. 2) and the back-trajectory modelling indicating that the dust plume was about six days old. For comparison, SD transport to the Caribbean typically takes 5-7 days (Prospero and Carlson 1981) and to central Europe as little as 3-5 days (Müller et al., 2003; Collaud Coen et al., 2004).

Optical depths exceeding that reported here, $\tau \approx 0.3$, are a common feature of SD episodes, even at locations distant from dust sources (Reid et al., 2003a; Müller et al., 2003). For high values of $\tau$ the dust layer conductivity can drop to low values, in accordance with Eq. (7). In the limiting case of the resistance of the layer being much higher than the resistance of the rest of the column the full ionosphere-Earth electric potential difference would appear between the top and the bottom of the layer. In this case Eq. (12) simplifies to

$E=U / \Delta z$

(without taking into account the topographic enhancement). If we take $1 \mathrm{kV} / \mathrm{m}$ as the minimum field strength and the average ionospheric potential $U=280 \mathrm{kV}$ (Mühleisen, 1971), SD layers less than about $300 \mathrm{~m}$ in thickness could show alignment, provided that particles in the required size range are present. While thicker SD layers are more common, thicknesses of a few hundred meters have previously been observed over Europe (Müller et al., 2003; De Tomasi et al., 2003; Papayannis et al., 2005), the Azores (Chazette et al., 2001) and off Cape Verde Islands (Leon et al., 2003). A further factor is that the atmospheric electric field can be significantly stronger outside the time period when the polarization was measured at La Palma (mostly 22:00 to 05:00 h UTC) because of the diurnal cycle of the ionospheric potential, which shows a minimum at this time (Roble and Tzur, 1986). Therefore, we can conclude that selective particle 
alignment due to reduced conductivity could be a feature of SD layers in some circumstances. At the same time, alignment due to fields within charged dust layers may be more widespread.

In addition to being detectable through measurements of polarized extinction, dust alignment is very likely to influence angular scattering, both polarized and unpolarized, from mineral dust layers and so can have strong effect on remote sensing retrievals, as represented for example by almucantar measurements using sun photometers or angle-dependent polarimetry. While these issues are too complex to be examined here, our results already indicate that the alignment can significantly alter the optical depth of the dust layer, and make it anisotropic. Figure 11 shows that for the case reported here the optical thickness in the vertical direction can decrease due to the alignment by as much as $10 \%$ at the wavelength of $780 \mathrm{~nm}$. From the ray optics point of view, this phenomenon can be likened to a "Venetian blind", whereby grains aligned preferentially in the vertical direction tend to pass through more radiation due to reduced cross-section. Moreover, while the alignment makes the layer anisotropic, the reduction in optical depth is not very strongly dependent on the angle of incidence for low solar zenith angles: for example, the decrease corresponding to the $20^{\circ}$ zenith angle is still $8 \%$. Hence the influence would not be limited to the lowest latitudes or the time around noon, although that is when the extinction would be most strongly affected.

In addition to random orientation that can be expected of smaller particles, particles above the optimum size range for electric alignment may align with their long axis horizontal (Sassen and Benson, 2001; Weinheimer and Few, 1987). This could, in principle, cancel or even reverse the sign of the observed polarization, as shown by the negative values in Fig. 10 for $E=800 \mathrm{~V} / \mathrm{m}$. However, the larger particles would be present in most cases in the tail of the dust size distribution (Fig. 5), and as such would be likely to contribute less to the overall extinction than the electrically aligned ones, provided that the field is sufficiently strong.

We should examine other possible factors influencing the postulated presence of strong electric fields over La Palma. One such factor is surface topography. As discussed in Sect. 2.3, fields over mountaintops can be enhanced by a factor of two or so. Furthermore, a reduction in the thickness of the aerosol layer due to orographic flow could augment the field in accordance with Eq. (18). Over flat terrain these effects would not be present, potentially reducing the strength of the alignment originating from the depletion of atmospheric conductivity. However, surface topography is less likely to have influence on fields within charged aerosol layers, especially if the field is due to a dipole (charge separation).

To evaluate the factors discussed here, future highsensitivity polarized extinction measurements should be carried out at low altitude as well as at mountaintop locations and to include lidar as a means of vertical profiling of aerosols. It is also highly desirable to make simultaneous measurements of electrical properties of the atmosphere, including field strength, current density and conductivity. Field measurements in particular should also be carried out from an airborne platform. Such observations will make it possible to estimate the influence that dust alignment may have on remote sensing retrievals and the radiative balance of the atmosphere.

Measurements of polarized extinction could also be used to study crystal alignment in cirrus clouds. We estimate that this should be possible for optical thickness values at least an order of magnitude lower than during the La Palma event, i.e. down to about 0.03 (the threshold for subvisual cirrus).

\section{Conclusions}

Optical polarimetry observations during a Saharan dust episode showed dichroic extinction, indicating the presence in the atmosphere of particles aligned preferentially in the vertical direction. It is postulated that the observed dust alignment was caused by an electric field within the dust layer. The minimum field required to partially align slightly nonspherical $\approx 10-20 \mu \mathrm{m}$ particles is of the order of $1 \mathrm{kV} / \mathrm{m}$, although some effects may be observable for even smaller field strengths. For the observations in question the field strength is estimated at $2 \mathrm{kV} / \mathrm{m}$. The field may have been present because of the depletion of atmospheric conductivity due to the dust. However, as shown by Fig. 6, for sufficient field strengths to be present the dust layer needs to be rather thin $-100-200 \mathrm{~m}$ - which is possible but not very likely for the aged dust cloud in question. In contrast, fields accompanying charged dust clouds appear to be stronger, and could in principle produce the required alignment. In addition to being detectable through polarization, the alignment significantly alters the optical depth of the dust layer, decreasing it by about $10 \%$ in the vertical direction for the case reported here. This reduction is dependent on the angle of incidence because of the induced anisotropy of the layer. One implication of the anisotropy, important for both modelling of radiative properties and for remote sensing retrievals, is that the radiative transfer models used would have to include particle alignment; such models are increasingly used in astronomy (Whitney and Wolff, 2002; Lucas, 2003) but are rare in atmospheric science. It is also conjectured that the existence of the electric field may provide a mechanism for the hypothetical process that appears to counteract gravitational settling of larger particles in SD layers (Maring et al., 2003). In contract, gravitational settling of nonspherical particles would be increased by the vertical alignment, which could explain the apparent scarcity of elongated particles in dust samples collected after longer range transport (Li and Osada, 2007).

Because the dust episode did not seem to be exceptional in meteorological terms, and the properties of the dust cloud were likely to be typical of a large geographical area, the 
alignment may be a common feature of Saharan dust layers. However, questions concerning the precise origin, magnitude, extent and influence of the phenomenon investigated here will remain unresolved until more systematic polarimetric observations, ideally accompanied by lidar sounding and measurements of electrical properties, can be carried out.

Acknowledgements. The authors gratefully acknowledge the NOAA Air Resources Laboratory for the provision of the HYSPLIT transport model used in this publication. We thank Emilio Cuevas for maintaining the sun photometer on the Santa Cruz site and the AERONET network for providing the data. MODIS data used in this study were acquired as part of the NASA's Earth-Sun System Division and archived and distributed by the Goddard Earth Sciences Distributed Active Archive Center. The OMI images and data were acquired using the GES-DISC Interactive Online Visualization ANd aNalysis Infrastructure (GIOVANNI) as part of the NASA's Goddard Earth Sciences Data and Information Services Center; OMI is a joint effort of KNMI, NASA, and FMI, and is managed by NIVR/Netherlands. We also acknowledge a PPARC (now STFC) grant to build PlanetPol. Finally, we thank the anonymous reviewers, as well as T. Nousiainen and O. Kalashnikova, whose comments helped us improve the final article.

Edited by: A. Pszenny

\section{References}

Andreae M. O., Jones, C. D., and Cox, P. M.: Strong present-day aerosol cooling implies a hot future, Nature, 435, 1187-1190, 2005.

Boesche, E., Stammes, P., Ruhtz, T., Preusker, R., and Fischer J.: Effect of aerosol microphysical properties on polarization of skylight: sensitivity study and measurements, Appl. Optics, 45, 8790-8805, 2006.

Brazenor, T. J. and Harrison, R. G. : Aerosol modulation of the optical and electrical properties of urban air, Atmos. Environ., 39, 5205-5212, 2005.

Caylor, I. J. and Chandrasekar, V.: Time-varying ice crystal orientation in thunderstorms observed with multiparameter radar, IEEE Trans. Geosci. Remote Sensing, 34, 847-868, 1996.

Chazette, P., Pelon, J., Moulin, C., Dulac, F., Carrasco, I., Guelle, W., Bousquet, P., and Flamant, P. H.: Lidar and satellite retrieval of dust aerosols over the Azores during SOFIA/ASTEX, Atmos. Environ., 35, 4297-4304, 2001.

Clement, C. F., Clement, R. A., and Harrison, R. G.: Charge distributions and coagulation of radioactive aerosols, J. Aerosol Sci., 26, 1207-1225, 1995.

Clift, R., Grace, J. R., and Weber, M. E.: Bubbles drops and particles, Academic Press, New York, 1978.

Cobb, W. E., Phillips, B. B., and Allee, P. A.: Note on mountain-top measurements of atmospheric electricity in northwestern United States, Monthly Weather Rev., 95, 912-916, 1967.

Cobb, W. E.: The atmospheric electric climate at Mauna Loa, J. Atmos. Sci., 25, 470-480, 1968.

Colarco, P. R., Toon, O. B., Torres, O., and Rasch, P. J.: Determining the UV imaginary index of refraction of Saharan dust particles from Total Ozone Mapping Spectrometer data using a three-dimensional model of dust transport, J. Geophys. Res., 107, 4289, doi:10.1029/2001JD000903, 2002.

Collaud Coen, M., Weingartner, E., Schaub, D., Hueglin, C., Corrigan C., Henning, S., Schwikowski, M., and Baltensperger, U.: Saharan dust events at the Jungfraujoch: detection by wavelength dependence of the single scattering albedo and first climatology analysis, Atmos. Chem. Phys., 4, 2465-2480, 2004, http://www.atmos-chem-phys.net/4/2465/2004/.

Cox, R. G.: The steady motion of a particle of arbitrary shape at small Reynolds numbers, J. Fluid Mech., 23, 625-643, 1965.

De Tomasi F., Blanco, A., and Perrone, M. R.: Raman lidar monitoring of extinction and backscattering of African dust layers and dust characterization, Appl. Optics, 42, 1699-1709, 2003.

Draxler, R. R. and Rolph, G. D.: HYSPLIT (HYbrid SingleParticle Lagrangian Integrated Trajectory) Model access via NOAA ARL READY website http://www.arl.noaa.gov/ready/ hysplit4.html, NOAA Air Resources Laboratory, Silver Spring, 2003.

Dubovik, O., Sinyuk, A., Lapyonok, T., et al.: Application of spheroid models to account for aerosol particle nonsphericity in remote sensing of desert dust, J. Geophys. Res., 111, D11208, doi:10.1029/2005JD006619, 2006.

Evan, A. T., Dunion, J., Foley, J. A., Heidinger, A. K., and Velden, C. S.: New evidence for a relationship between Atlantic tropical cyclone activity and African dust outbreaks, Geophys. Res. Lett., 33, L19813, doi:10.1029/2006GL026408, 2006.

Ette, A. I. I.: The effect of Harmattan dust on atmosphere electric parameters, J. Atmos. Terr. Phys., 33, 295-300, 1971.

Farrell, W. M., Smith, P. H., Delory, G. T., et al.: Electric and magnetic signatures of dust devils from the 2000 2001 MATADOR desert tests, J. Geophys. Res., 109, E03004, doi:10.1029/2003JE002088, 2004.

Frier, G. D.: The electric field of a large dust devil, J. Geophys. Res., 65, p. 3504, 1960.

Fuchs, N. A.: On the stationary charge distribution on aerosol particles in a bipolar ionic atmosphere, Geofis. Pura Appl., 56, 185197, 1963.

Fuchs, N. A.: Mechanics of aerosols, Pergamon, Oxford, 1964.

Ginoux, P., Chin, M., Tegen, I., Prospero, J. M., Holben, B., Dubovik, O., and Lin, S.-J.: Sources and distributions of dust aerosols simulated with the GOCART model, J. Geophys. Res., 106, 20 255-20 273, doi:10.1029/2000JD000053, 2001.

Goudie, A. S. and Middleton, N. J.: Saharan dust storms: nature and consequences, Earth Sci. Rev., 56, 179-204, 2001.

Gringel, W. and Mühleisen, R.: Sahara dust concentration in the troposphere over the North Atlantic derived from measurements of air conductivity, Beitr. Physik Atmos., 51, 121-128, 1978.

Gringel, W., Rosen, J. M., and Hofmann, D. J.: Electrical structure from 0 to 30 kilometers, in: The Earth's Electrical Environment, National Academy Press, Washington, 166-182, 1986.

Harris, D. J.: Electrical effects of the Harmattan dust storms, Nature, 214, p. 585, 1967.

Harrison, R. G. and Aplin, K. L.: Mid-nineteenth century smoke concentrations near London, Atm. Env., 36, 4037-4043, 2002.

Harrison, R. G. and Ingram, W. J.: Air-earth current measurements at Kew, London, 1909-197, Atmos. Res., 76, 49-64, 2005.

Haywood, J. M., Allan, R. P., Culverwell, I., Slingo, T., Milton, S., Edwards, J., and Clerbaux, N.: Can desert dust explain the outgoing longwave radiation anomaly over the Sa- 
hara during July 2003?, J. Geophys. Res., 110, D05105, doi:10.1029/2004JD005232, 2005.

Hendry, A. and McCormick, G. C.: Radar observations of the alignment of precipitation particles by electrostatic fields in thunderstorms, J. Geophys. Res., 81, 5353-5357, 1976.

Hoppel, W. A. and Frick, G. M.: Ion-aerosol attachment coefficients and the steady-state charge distribution on aerosols in a bipolar ion environment, Aerosol Sci. Technol., 5, 1-21, 1986.

Hough, J. H.: New opportunities for astronomical polarimetry, J. Quantit. Spectr. Rad. Transfer, 106, 122-132, 2007.

Hough, J. H., Lucas, P. W., Bailey, J. A., Tamura, M., Hirst, E., Harrison, D., and Bartholomew-Biggs, M.: PlanetPol: a very high sensitivity polarimeter, Publ. Astron. Soc. Pac., 118, 13021318, 2006.

Kahnert, M., Nousiainen, T., and Veihelmann, B.: Spherical and spheroidal model particles as an error source in aerosol climate forcing and radiance computations: A case study for feldspar aerosols, J. Geophys. Res., 110, D18S13, doi:10.1029/2004JD005558, 2005.

Kalashnikova, O. V. and Sokolik, I. N.: Importance of shapes and compositions of wind-blown dust particles for remote sensing at solar wavelengths, Geophys. Res. Lett., 29, 38.1-38.4, 2002.

Kamra, A. K.: Measurements of electrical properties of dust storms. J. Geophys. Res., 77, 5856-5869, 1972.

Karyampudi, V. M., Palm, S. P., Reagen, J. A., et al.: Validation of the Saharan dust plume conceptual model using lidar, Meteosat, and ECMWF data, B. Am. Meteorol. Soc., 80, 1045-1076, 1999.

Kasemir, H. W.: Theoretical problems of the global atmospheric electric circuit, in: Electrical processes in atmospheres, Dolezalek, H. (ed.), Steinkopf, Darmstadt, 423-438, 1977.

Krehbiel, P., Chen T., McCrary S., Rison W., Gray, G., and Brook, M.: The use of dual channel circular-polarization radar observations for remotely sensing storm electrification, Meteorol. Atmos. Phys., 59, 65-82, 1996.

Kocijan, F.: The natural geoelectric field, in: Proc. 2nd Int. Conf. Bioelectromagnetism, Melbourne, IEEE, Piscataway, 137-138, 1998.

Le Ny, R.: The electrostatic problem of a portion of sphere protruding from a plane electrode in an electric field, J. Phys. A, 14, 945-955, 1981.

Leon, J.-F., Tanre, D., Pelon, J., Kaufman, Y. J., Haywood, J. M., and Chatenet, B.: Profiling of a Saharan dust outbreak based on a synergy between active and passive remote sensing, J. Geophys. Res., 108, 8575, doi:10.1029/2002JD002774, 2003.

Li, Z., Goloub, P., Blarel, L., Damiri, B., Podvin, T., and Jankowiak, I.: Dust optical properties retrieved from ground-based polarimetric measurements, Appl. Opt., 46, 1548-1553, 2007.

Li, J. and Osada, K.: Water-insoluble particles in spring snow at Mt. Tateyama, Japan: Characteristics of the shape factors and size distribution in relation with their origin and transportation, J. Meteorol. Soc. Jpn, 85, 137-149, 2007.

Li, J. and Osada, K.: Preferential settling of elongated mineral dust particles in the atmosphere, Geophys. Res. Lett., 34, L17807, doi:10.1029/2007GL030262, 2007a.

Lilienfeld, P.: Rotational electrodynamics of airborne fibers, J. Aerosol Sci., 16, 315-322, 1985.

Lucas, P. W.: Computation of light scattering in young stellar objects, J. Quantit. Spectr. Rad. Transf., 79-80, 921-937, 2003.

Maring, H., Savoie, D. L., Izaguirre, M. A., Custals, L., and
Reid, J. S.: Mineral dust aerosol size distribution change during atmospheric transport, J. Geophys. Res., 108, 8592, doi:10.1029/2002JD002536, 2003.

Mather, T. A. and Harrison, R. G.: Electrification of volcanic plumes, Surv. Geophys., 27, 387-432, 2006.

Melnik, O. and Parrot, M.: Electrostatic discharge in Martian dust storms, J. Geophys. Res., 103, A29107-A29117, 1998.

Mendez, D. J.: Optical polarization induced by electric fields of thunderstorms, J. Geophys. Res., 74, 7032-7037, 1969.

Middleton, N. J., Betzer, P. R., and Bull, P. A.: Long-range transport of 'giant' aeolian quartz grains: linkage with discrete sedimentary sources and implications for protective particle transfer, Marine Geol., 177, 411-417, 2001.

Mishchenko, M. I.: Calculation of the amplitude matrix for a nonspherical particle in a fixed orientation, Appl. Optics, 39, 10261031, 2000.

Mishchenko, M. I, Geogdzhayev, I. V., Liu, L., Ogren, J. A., Lacis, A. A., Rossow, W. B., Hovenier, J. W., Volten, H., and Muñoz, O.: Aerosol retrievals from AVHRR radiances: effects of particle nonsphericity and absorption and an updated long-term global climatology of aerosol properties, J. Quantit. Spectrosc. Radiat. Transfer, 79/80, 953-972, 2003.

Mishchenko, M. I., Geogdzhayev, I. V., Cairns, B., Carlson, B. E., Chowdhary, J., Lacis, A. A., Liu, L., Rossow, W. B., and Travis, L. D.: Past, present, and future of global aerosol climatologies derived from satellite observations: a perspective, J. Quantit. Spectrosc. Radiat. Transfer, 106, 325-347, 2007.

Mishchenko, M. I., Travis, L. D., and Lacis, A. A.: Scattering, Absorption, and Emission of Light by Small Particles, Cambridge University Press, Cambridge, 2002.

Mühleisen, R.: Neue Ergebnisse und Probleme in der Luftelektrizität, Z. Geoph., 37, 759-793, 1971.

Müller, D., Mattis, I., Wandinger, U., Ansmann, A., Althausen, D., Dubovik, O., Eckhardt, S., and Stohl, A.: Saharan dust over a Central European EARLINET-AERONET site: Combined observations with Raman lidar and sun photometer, J. Geophys. Res., 108, 4345, doi:10.1029/2002JD002918, 2003.

Myhre, G., Grini, A., Haywood, J. M., Stordal, F., Chatenet, B., Tanre, D., Sundet, J. K., and Isaksen, I. S. A.: Modeling the radiative impact of mineral dust during the Saharan Dust Experiment (SHADE) campaign, J. Geophys. Res., 108, 8579, doi:10.1029/2002JD002566, 2003.

Oluwafemi, C. O. and Ette, A. I. I.: On the vertical distribution of space charge during the Harmattan, J. Geophys. Res., 79, 871872, 1974.

Papayannis, A., Amiridis, V., Bösenberg, J., et al.: First systematic observations of Saharan dust over Europe (2000-2003): Statistical analysis and results, Geophys. Res. Abstr., 7, 04016, 2005.

Pitty, A. F.: Particle size of the Saharan dust which fell in Britain in July 1968, Nature, 220, 364-365, 1968.

Platt, C. M. R., Abshire, N. L., and McNice, G. T.: Some microphysical properties of an ice cloud from lidar observation of horizontally oriented crystals, J. Appl. Meteor., 17, 1220-1224, 1978.

Prigent, C., Defer, E., Pardo, J. R., Pearl, C., Rossow, W. B., and Pinty, J.-P.: Relations of polarized scattering signatures observed by the TRMM Microwave Instrument with electrical processes in cloud systems, Geophys. Res. Lett., 32, L04810, doi:10.1029/2004GL022225, 2005. 
Prospero, J. M. and Carlson, T. N.: Saharan air outbreaks over the tropical North Atlantic, Pure Appl. Geophys., 119, 677-691, 1981.

Ratmeyer, V., Balzer, W., Bergametti, G., Chiapello, I., Fischer, G., and Wyputta, U.: Seasonal impact of mineral dust on deepocean particle flux in the eastern subtropical Atlantic Ocean, Mar. Geol., 159, 241-252, 1999.

Reid, J. S., Jonsson, H. H., Maring, H. B., et al.: Comparison of size and morphological measurements of coarse mode dust particles from Africa, J. Geophys. Res., 108, 8593, doi:10.1029/2002JD002485, 2003.

Reid, J. S., Kinney, J. E., Westphal, D. L., et al.: Analysis of measurements of Saharan dust by airborne and groundbased remote sensing methods during the Puerto Rico Dust Experiment (PRIDE), J. Geophys. Res., 108, 8586, doi:10.1029/2002JD002493, 2003a.

Reiter, R: Phenomena in atmospheric and environmental electricity, Elsevier, Amsterdam, 1992.

Roble, R. G. and Tzur, I.: The global atmospheric electric circuit, in: The Earth's Electrical Environment, National Academy Press, Washington, 206-231, 1986.

Sassen, K. and Benson, S.: A midlatitude cirrus cloud climatology from the Facility for Atmospheric Remote Sensing. II. Microphysical properties derived from lidar depolarization, J. Atmos. Sci., 58, 2103-2112, 2001.

Schottky, W.: Über kalte und warme Elektronenentladungen, Z. Physik A, 14, 63-106, 1923.

Scrase, F. J.: Observations of atmospheric electricity at Kew observatory, Geophysical Memoirs 60, HMSO, London, 1934.

Scrase, F. J.: The charged and uncharged nuclei in the atmosphere and their part in atmospheric ionisation, Geophysical Memoirs 64, HMSO, London, 1935.
Smirnov, A., Holben, B. N., Slutsker, I., Welton, E. J., and Formenti, P.: Optical properties of Saharan dust during ACE 2, J. Geophys. Res., 103, 28 079-28 092, 1998.

Smirnov, V. V.: Electric fields of dust streams, Fiz. Atmos. Okeana, 35, 616-623, 1999.

Varela, A. M., Fuensalida, J. J., Muñoz-Tuñón, C., Rodríguez Espinosa, J. M., García-Lorenzo B. and Cuevas, E.: Comparison of the aerosol index from satellites and the atmospheric extinction coefficient above the Canarian observatories, in: Ground-based Telescopes, edited by: Oschmann, J. M. Proc. SPIE 5489, 245255, 2003.

Volten, H., Muñoz, O., Hovenier, J. W., de Haan, J. F., Vassen, W., and van der Zande, W. J.: WWW scattering matrix database for small mineral particles at 441.6 and $632.8 \mathrm{~nm}$, J. Quantit. Spectrosc. Radiat. Transfer, 90, 191-206, 2005.

Vonnegut, B.: Orientation of ice crystals in the electric field of a thunderstorm, Weather, 20, 310-312, 1965.

Weinheimer, A. J. and Few, A. A.: The electric field alignment of ice particles in thunderstorms, J. Geophys. Res., 92, $14833-$ $14844,1987$.

Whitney, B. A. and Wolff, M. J.: Scattering and absorption by aligned grains in circumstellar environments, Astrophys. J., 574, 205-231, 2002.

Wright, H. L.: The influence of atmospheric suspensoids upon the earth's electric field as indicated by observations at Kew observatory, Proc. Phys. Soc. (London), 45, 152-171, 1933.

Wu, L. G.: Impact of Saharan air layer on hurricane peak intensity, Geophys. Res. Lett., 34, L09802, doi:10.1029/2007GL029564, 2007.

Yu, H., Kaufman, Y. J., Chin, M., et al.: A review of measurementbased assessments of the aerosol direct radiative effect and forcing, Atmos. Chem. Phys., 6, 613-666, 2006, http://www.atmos-chem-phys.net/6/613/2006/. 